\title{
PENGARUH PELATIHAN PERCEPTORSHIP TERHADAP TINGKAT PENGETAHUAN, SIKAP PEMBIMBING KLINIK DAN KEPUASAN MAHASISWA DALAM PROSES BIMBINGAN DI KLINIK
}

\author{
C.Ermayani Putriyanti ${ }^{1}$, Ganjar Unggul Pamenang ${ }^{2}$, Suwarsono $^{3}$ \\ ${ }^{1}$ Departemen Keperawatan Anak, Akademi Keperawatan Ngesti Waluyo \\ ${ }^{2,3}$ Departemen Keperawatan Komunitas, Akademi Keperawatan Ngesti Waluyo
}

Korespondensi penulis, e-mail: ermayaniputriyanti@gmail.com

\begin{abstract}
ABSTRAK
Perceptorship merupakan strategi pembelajaran klinik, yang ditujukan membantu seorang calon perawat memasuki dunia keperawatan yang menguasai pengetahuan, sikap, ketrampilan dan komunikasi yang efektif agar dapat memberikan asuhan keperawatan sesuai kewewangan dan tanggungjawabnya. Pelatihan Perceptorship bagi Pembimbing Klinik diharapkan dapat memberi bimbingan yang memuaskan bagi Mahasiwa yang akan mengikuti praktek klinik di suatu Rumah Sakit. Tujuan penelitian yaitu untuk melihat pengaruh pelatihan perceptorship terhadap tingkat pengetahuan, sikap pembimbing klinik dan kepuasan mahasiswa dalam proses bimbingan di klinik. Penelitian ini menggunakan Mixed Methods. Penelitian kuantitatif dengan rancangan "pre test and post test", menggunakan Uji Paired Sample $T$ Test. Pada penelitian kualitatif menggunakan wawancara mendalam dengan panduan yang telah disiapkan. Objek penelitian kuantitatif adalah semua pembimbing klinik sebanyak 24 orang yang mengikuti pelatihan perceptorship, , responden penelitian kualitatif adalah mahasiswa yang mendapatkan bimbingan dari pembimbing klinik yang telah mendapatkan pelatihan perceptorship. Uji Paired Sampel T Test menunjukkan hasil pre test dan post test pelatihan perceptorship dengan signifikansi $\mathrm{p}=0.000$, dan hasil wawancara mendalam kepada semua responden terhadap proses bimbingan klinik menunjukkan respon yang baik, senang dan puas terhadap proses bimbingan di klinik. Disimpulkan bahwa ada pengaruh pelatihan perceptorship terhadap tingkat pengetahuan, sikap pembimbing klinik, dan terdapat kepuasan mahasiswa yang mendapat bimbingan dari para pembimbing klinik yang telah mendapatkan pelatihan perceptorship.
\end{abstract}

Kata Kunci : Perceptorship, pembimbing klinik, proses bimbingan di klinik

\section{PENDAHULUAN}

Keperawatan merupakan salah satu profesi yang unik dan mulia, hal ini dikarenakan perawat berhadapan langsung dengan pasien yang bukan saja mengalami masalah kesehatan fisik namun masalah psikologis nya pun ikut terganggu akibat masalah fisik yang diderita. Dalam memberikan asuhan keperawatan, profesi ini harus siap melayani pasien selama 24 jam. Adapun lingkup asuhan keperawatan yang diberikan oleh perawat bersifat komprehensif atau menyeluruh baik secara biopsikososial, spiritual dan kultural. Secara tidak langsung seorang perawat dituntut menguasai pengetahuan, sikap dan skill yang baik, agar dapat memberikan asuhan keperawatan 
secara profesional. Kondisi ini secara tidak langsung berdampak pula pada proses pembelajaran seorang calon perawat. Institusi pendidikan dan lahan praktik keperawatan bertanggungjawab dalam menyiapkan calon perawat. Namun yang terjadi saat ini masih banyak ditemukan kesenjangan antara teori yang diberikan di kelas /kampus dan praktik dalam proses bimbingan di klinik yang diberikan kepada calon perawat atau mahasiswa. Hal ini sering menyebabkan mahasiswa sering mengalami kesulitan dalam beradaptasi di lahan praktik. (Dadgaran, Parvizy, \& Peyrovi, 2012)

. Para pembimbing klinik tidak berasal dari latar belakang pendidik yang menguasai ilmu pedagogik, hal ini sering menjadi kendala ketika melakukan bimbingan kepada mahasiswa diklinik terlebih terkait strategi mengajar, pendampingan mahasiswa di klinik, teknik evaluasi pembelajaran klinik, serta membantu mahasiswa untuk beraktualiasasi diri. Perbedaan metode bimbingan yang diterima oleh mahasiswa di klinik dan kampus kadang menimbulkan persoalan tersendiri bagi mahasiswa. Di kampus mahasiwa lebih fokus pada konsep-konsep yang harus dikuasai oleh seorang calon perawat, saat praktik klinik mahasiswa harus berhadapan dengan pasien yang sesungguhnya. Walaupun di laboratorium keperawatan mahasiswa juga melakukan praktik dengan probandus atau orang yang berperan sebagai pasien, namun hal ini tetap saja berbeda ketika mahasiswa harus berhadapan langsung dengan pasien yang nyata. Kondisi ini sering menyebabkan mahasiswa merasa cemas, bingung, dan tidak percaya diri ketika berhadapan langsung dengan klien dan keluarga. Di satu sisi mahasiswa juga harus beradaptasi dengan lingkungan praktik, berinteraksi dengan perawat dan tenaga kesehatan lainnya.

Peran pembimbing klinik sangat besar dalam menghantarkan lulusan yang berkompeten. Lingkungan praktik yang kondusif serta menyenangkan sangat berpengaruh terhadap minat mahasiswa dalam menekuni profesi keperawatan. Banyak mahasiswa keperawatan sejak awal mengikuti pendidikan keperawatan bukan dari dorongan hatinya namun lebih kepada keinginan orangtua atau yang penting cepat mendapat pekerjaan. Perasaan cemas, bingung, tidak percaya diri, sulit memutuskan sesuatu sering dialami sebagian besar mahasiswa ketika praktik klinik. Pembimbing klinik bertanggungjawab mengidentifikasi kekuatan dan kemampuan mahasiswa, dimana kekuatan tersebut menjadi modal mahasiswa dalam menyelesaikan permasalahan yang ada (Cederbaum, \& Klusaritz, 2009)

$\begin{array}{cc}\text { Metode } & \text { Perceptorship } \\ \text { merupakan strategi pembelajaran }\end{array}$ klinik, yang ditujukan untuk membantu mahasiswa memasuki dunia keperawatan agar dapat menguasai pengetahuan, sikap, ketrampilan dan komunikasi yang efektif, agar kedepannya dapat memberikan asuhan keperawatan sesuai kewewangan dan tanggungjawabnya. Kepuasan merupakan pernyataan yang diungkapkan seseorang meliputi ungkapan perasaan senang atau kecewa setelah membandingkan terhadap kinerja atau produk yang dirasakan atau diharapkannya. 


\section{METODE}

Metode penelitian ini menggunakan Mixed Methods dengan menggabungkan penelitian kuantitatif dan penelitian kualitatif. Pada penelitian kuantitatif ini semua anggota populasi pembimbing klinik dilakukan tindakan pre test dan post test, dengan menggunakan Uji Paired Sample $T$ Test. Objek penelitian kuantitatif adalah semua pembimbing klinik yang mengikuti pelatihan preceptorship. Sebelum dilakukan tindakan, semua obyek penelitian mengikuti pre test dan setelah tindakan semua objek mengikuti post test untuk mengamati pengaruh tindakan terhadap pengetahuan dan sikap dari pembimbing klinik yang mengikuti pelatihan perceptorship. Penelitian ini juga menggunakan pendekatan kualitatif eksploratif yang dilakukan kepada para mahasiswa yang mendapat bimbingan dari para pembimbing klinik yang telah mendapatkan pelatihan preceptorship untuk diamati kepuasan mahasiswa dalam proses bimbingan klinik yang diberikan oleh para pembimbing yang telah mendapatkan pelatihan preceptorship. Pemilihan responden dilakukan dengan teknik purposive sampling yang terdiri atas 2 mahasiswa berjenis kelamin perempuan dan 1 mahasiswa berjenis kelamin laki-laki. Masing-masing responden mewakili tiap ruangan praktik. Penggambilan data menggunakan wawancara mendalam dengan pertanyaan terbuka dengan panduan yang telah disiapkan. Penelitian dilakukan di sebuah rumah sakit swasta di Kota Magelang Jawa Tengah dari bulan Juli-Agustus 2019.

\section{HASIL}

$\begin{array}{rrr}\text { Gambaran dari } & \text { peserta } \\ \text { pelatihan preceptorship } & \text { sebagai }\end{array}$

berikut: peserta adalah semua pembimbing klinik yang ditunjuk oleh pihak rumah sakit yang direncanakan untuk mendampingi dan membimbing mahasiswa keperawatan ketika berpraktik di rumah sakit. Jumlah peseta pelatihan sebanyak 24 orang, Sebanyak 91,67\% berlatarbelakang pendidikan Diploma Tiga Keperawatan dan 8,33 \% memiliki pendidikan Sarjana Keperawatan. Dua orang peserta sebelumnya sudah pernah mendapatkan pelatihan pembimbing klinik, namun lebih dari 5 tahun yang lalu. Sedangkan peserta lainnya belum pernah mendapatkan pelatihan preceptorship atau pembimbing klinik. Para peserta pelatihan memiliki pengalaman kerja sebagai berikut: (Pengalaman $<5$ tahun $=8$ orang), (Pengalaman 5-10 tahun $=6$ orang), (Pengalaman $>10$ tahun $=10$ orang).

Pelatihan

preceptorship merupakan kerjasama antara rumah sakit lahan praktik dan institusi pendidikan. Sebelum pelatihan semua peserta mengikuti pre test, tindakan ini bertujuan melihat sejauhmana pengetahuan dan sikap peserta terkait pengantar preceptorship, pembelajaran orang dewasa, lingkungan pembelajaran klinik, aspek etikolegal dalam bimbingan mahasiswa praktik, metode bimbingan, komunikasi efektif, meningkatkan rasa nyaman \& pengakuan kapasitas mahasiswa. Setelah mendapatkan pelatihan para peserta mengikuti post test untuk mengetahui sejauhmana pengaruh pelatihan perceptorship terhadap pengetahuan dan sikap pembimbing klinik. Passing Grade atau Nilai Batas Lulus (NBL) yang ditetapkan adalah 70.

Penyampaian materi dalam pelatihan perceptorship menggunakan 
metode ceramah, diskusi, tanya jawab dan bermain peran atau role play untuk pendekatan pre-post conference, bed side teaching, ronde keperawatan, coaching, dan proses bimbingan kepada mahasiswa yang bermasalah ketika melaksanakan praktik klinik. Berikut ini gambaran hasil pelatihan preceptorship bagi pembimbing klinik:

Tabel 1. Hasil Paired Sampel T Test Pengaruh Pelatihan Perceptorship terhadap Tingkat Pengetahuan dan Sikap Pembimbing Klinik

\begin{tabular}{|l|l|l|l|l|l|}
\hline Pengetahuan & $\mathbf{N}$ & Mean \pm SD & Perbedaan Rerata \pm s.d & IK 95\% & p \\
\hline Pre Test & 2 & $56.67 \pm 10.0$ & $-19.583 \pm 13.667$ & $-25.354-$ & 0.000 \\
& 4 & 72 & & -13.812 & \\
\hline Post Test & 2 & $76.25 \pm 7.10$ & & & \\
& 4 & 9 & & & \\
\hline
\end{tabular}

Hasil pre test dan post test dilakukan kepada pembimbing klinik pada pelatihan perceptorship, menggunakan Uji Paired Sampel T Test menunjukkan ada pengaruh pemberian pelatihan perceptorship terhadap tingkat pengetahuan dan sikap pembimbing klinik, hal ini ditunjukkan ada signifikansi dengan $\mathrm{p}=0.000$.

Penelitian dilanjutkan dengan observasi dan wawancara mendalam kepada mahasiswa semester $\mathrm{V}$ yang sedang menjalankan praktik klinik untuk pencapaian kompetensi keperawatan kritis, keperawatan kegawatdaruratan, dan di ruang kamar operasi. Jumlah praktikan sebanyak 10 orang, praktik klinik berlangsung satu bulan dari 5 Agustus -30 Agustus 2019. Wawancara mendalam dilakukan kepada salah satu perwakilan mahasiswa ditiap ruangan yang mendapatkan bimbingan langsung dari para pembimbing klinik yang telah mendapatkan pelatihan preceptorship. Wawancara mendalam dengan menggunakan panduan wawancara yang telah disiapakan. Pertanyaan kepada responden meliputi : pengetahuan, sikap, keterampilan dan kemampuan berkomunikasi pembimbing klinik terhadap mahasiswa Berikut hasil wawancara mendalam terhadap responden :

\section{Pengetahuan pembimbing}

"Bagus banget bu bimbingan disini, kebetulan saya diruangan ICU buk, saya gak tahu kalau diruangan lainya, kalau disini, teorinya juga bagus buk. Kemarin itu saya diminta mengelola pasien sekalian dokumentasi keperawatannya buk" (A-1).

"Menurut kelompok saya yang di UGD kemarin enak bu, pembimbingnya sama seniornya ngajarin secara detail dan sesuai SOP, terus kemarin kita juga diajarin secara khusus tentang pembelajaran dasar EKG, dosis obat, syering pump dan infus pump, kita juga banyak diajari cara-cara baru bu" (A-2).

"Pembimbingnya semangat sekali bu buat ngajarin mahasiswa, dari sistem zona, alat instrument, askep dan serah terima diajari juga bu'"(A-3)

Kesimpulan dari wawancara mendalam kepada tiga responden 
terhadap pengetahuan pembimbing menunjukkan bahwa pengetahuan pembimbing di klinik baik sesuai harapan mahasiswa.

\section{Sikap Pembimbing Klinik}

"Bagus perawatnya ramah-ramah buk, disiplin banget bu, kami gak boleh main HP, soalnya disana selama shift perawat gak boleh bawa HP" (A-1).

"Bagus bu, mereka banyak banget ngajari kami" (A-2).

"Pembimbingnya malah suka bu dengan AKPER kita bu, katanya anaknya peka-peka, malah perawat senior juga sering ngajari kami"'(A-3).

Kesimpulan dari wawancara mendalam kepada tiga responden menunjukkan, bahwa sikap pembimbing klinik baik yang ditunjukkan dari sikap pembimbing yang berusaha menciptakan lingkungan yang kondusif, bersahabat, mau mendampingi dan mengajari para mahasiswa yang memiliki keterbatasan dalam hal konsep dan skill di klinik. Observasi yang tampak dari ekspresi dan perilaku mahasiswa puas dengan sikap perawat yang bisa memberi keteladanan.

\section{Keterampilan Membimbing di Klinik}

"Mereka sering mengajak diskusi buk, kemarin pas ada beberapa kompetensi yang gak kecapai di ICU ya dibahas tidak langsung ke pasien" $(A-1)$.

"Kami kemarin diajari cara anamnesa terus lanjut pemilihan triase terus lanjut hand over cuman gitu bu. Kami diajari langsung disamping tempat tidur pasien" (A2).

“ Kami sering diajak diskusi bu ya tentang penyakit dan tindakan. Kami yang sering tanya kok", kami puas banget dengan bimbingan mas dan mbak disini" (A-3).

Kesimpulan dari ketiga responden menunjukkan semua pembimbing klinik terampil dalam membimbing yang ditunjukkan respon mahasiswa positif terhadap pembimbing, terlihat pembimbing menguasai apa yang menjadi kompetensinya, dan menguasai konsep pembimbingan dengan baik.

\section{Kemampuan Berkomunikasi}

"Bagus buk, komunikasi antar perawat bagus buk, dengan pasien juga bagus, pokoknya siip banget" (A-1).

"Bagus bu, seneng kami disana, kami sering sekali diajak diskusi tentang keperawatan, puas banget dengan bimbingan mereka" (A-2).

"Bagus bu pembimbingnya, kami betul-betul dibimbing, kalau sama kepala ruang kami jarang ketemu, beliau sibuk ngurusi operasi"'(A-3).

Kesimpulan dari tiga responden menunjukkan kemampuan berkomunikasi para pembimbing klinik bagus, Hal ini terlihat dari respon mahasiswa seperti ungkapan perasaan senang dan puas ketika menjalani praktik klinik selama satu bulan dibawah bimbingan pembimbing klinik yang telah mendapatkan pelatihan perceptorship. 


\section{PEMBAHASAN}

Pembelajaran praktik klinik keperawatan adalah rangkaian kegiatan berupa pengalaman peserta didik untuk menerapkan konsepkonsep yang telah diterima, untuk diaplikasikan ke kondisi yang nyata. Pemberian pelatihan Perceptorship kepada para pembimbing klinik sangat penting dilakukan untuk meningkatkan pengetahuan dan wawasan pembimbing dalam mendampingi peserta didik di klinik.

Hasil pre test dan post test diberikan kepada pembimbing klinik, yang mengikuti pelatihan perceptorship menunjukkan ada pengaruh pemberian pelatihan perceptorship terhadap tingkat pengetahuan pembimbing klinik, hal ini ditunjukkan hasil pre test dan post test menggunakan uji Paired Sample T Test dengan signifikansi $(\mathrm{p}=0.000)$.

Pembimbing klinik tidak hanya berperan sebagai pendidik, tetapi diharapkan dapat mendampingi dan bersosialiasi dengan peran barunya serta dapat mengetahui kebutuhan belajar mahasiswa. Mahasiswa yang baru pertama kali menjalani praktik klinik memiliki keterbatasan pengetahuan atau pengalaman di klinik, kadang mereka tidak mengetahui kebutuhan belajarnya.

Pada satu sisi mahasiswa harus menyelesaikan kompetensi yang ditargetkan institusi pendidikan, beradapatasi dengan lingkungan yang baru, bertemu dengan berbagai macam profesi, dan masih banyak lainnya. Pendampingan serta memberikan umpan balik sangat dibutuhkan mahasiswa, termasuk memberi kesempatan kepada mahasiswa untuk melihat, mencoba dan pada akhirnya mahasiswa dapat melakukannya secara mandiri kompetensi yang harus dikuasai (The Preceptor Role in Health Systems Management, 2019).

Pada penelitian ini tampak sekali para pembimbing klinik mengetahui dengan jelas tentang perannya sebagai pendidik yang memiliki pengetahuan membimbing dengan baik. Hal ini terungkap dari hasil wawancara mendalam ketiga responden yang semua menyatakan respon positif dan puas dengan cara pembimbing yang bersemangat dan berusaha memberikan pengetahuan klinik yang dibutuhkan mahasiswa.

Praktik klinik keperawatan merupakan pengalaman belajar bagi mahasiswa untuk mengaplikasikan teori yang sudah didapat kelahan praktik yang sesungguhnya, agar dapat beradaptasi dengan peran barunya. Keaktifan mahasiswa di klinik saat dibutuhkan, sehingga pengalaman yang berharga diklinik ini diharapkan dapat menjadi bekal nantinya mereka bekerja. Namun keaktifan mahasiswa di klinik tidak lepas dari peran pembimbing klinik, terlebih dalam menyikapi adanya kesenjangan antara teori dan praktik. Lingkungan praktik yang kondusif, bersahabat, memahami kebutuhan mahasiswa sangat mempengaruhi sikap mahasiswa terhadap profesi yang ditekuni saat ini (Akram \& Mohamad, 2018).

Pada penelitian ini tampak semua responden memberikan jawaban positif atau baik terhadap sikap pembimbing dan perawat lainnya yang ramah, tetapi tegas dapat menjadi role model atau teladan bagi mahasiswa. Situasi yang kondusif, support positif dari lingkungan sekitar diharapkan dapat mempengaruhi sikap mahasiswa yang sebelumnya tidak berminat di keperawatan, akhirnya menyenangi dunia keperawatan yang saat ini ditekuninya. Sikap saling percaya antara pembimbing dan 
mahasiswa, dapat mempengaruhi perilaku mahasiswa seperti berani bertanya, berani mencoba melakukan tindakan keperawatan dengan rasa percaya diri (Niederriter, 2017)

Pembimbing klinik merupakan pendidik bagi mahasiswa di klinik, seorang pendidik harus menjadi role model bagi peserta didiknya. Seorang pembimbing klinik diharapkan menjadi pemimpin yang fleksibel terhadap perubahan, selalu melakukan tindakan keperawatan berdasarkan evidence based. Selain itu pembimbing klinik diharapkan dapat menjadi motivator bagi peserta didiknya (Bura Mare \& Meidiana Dwidiyanti, 2018).

Hasil penelitian ini menunjukkan bahwa semua responden yang merupakan mahasiswa praktikan menyampaikan tanggapan bahwa pembimbing klinik selalu berusaha memberikan informasi-informasi yang perlu diketahui mahasiswa tentang peran dan tanggung jawab seorang perawat, mampu menyikapi permasalahan di klinik dengan bijaksana melalui memodifikasi metode pembelajaran yang dapat dipahami oleh mahasiswa, ketika di klinik kompetensi yang ditargetkan oleh institusi pendidikan tidak ada. Pembimbing

klinik diharapkan telah memiliki kemampuan komunikasi yang efektif, interpersonal dan memiliki kemampuan mengambil keputusan dengan baik. Komunikasi sangat penting bagi seorang perawat, namun beberapa mahasiswa hal ini bisa menjadi kendala, mengingat lahan praktik setiap semester yang berbedabeda lokasinya. Perbedaan persepsi bimbingan antar lahan praktik menyebabkan mahasiswa harus beradaptasi dengan lingkungan barunya.
Lingkungan yang kaku, sering membuat mahasiswa tidak berani mengutarakan pendapatnya terlebih ketika mahasiwa menemui perbedaan cara membimbing. Kondisi ini sering membuat pembimbing frustasi melihat mahasiswa pasif selama praktik, namun perlu diketahui bahwa pembimbing klinik harus menyadari peran dan tanggung jawabnya untuk berusaha menciptakan lingkungan praktik yang kondusif, berusaha menfasilitasi belajar mahasiswa dan berusaha semaksimal mungkin untuk merangsang bagaimana agar mahasiswa dapat aktif selama pembelajaran di klinik (Cederbaum, \& Klusaritz, 2009).

Pembimbing klinik perlu mengetahui bahwa kemampuan skill, hanya sebagian kecil dari perannya sebagai pembimbing. Hal terpenting dalam melakukan bimbingan klinik adalah berusaha meningkatkan kenyamanan, berusaha menjalin hubungan yang baik dan saling percaya dengan mahasiswa melalui diskusi, menyamakan persepsi terkait nilai-nilai profesi yang perlu diketahui oleh mahasiswa (O’Connor, 2015).

Hasil penelitian menunjukkan bahwa semua responden memberi jawaban bahwa mereka sangat senang menjalani praktik klinik. Hal ini terjadi karena pembimbing klinik sangat memperhatikan kenyamanan dan berusaha membuka diri menjalin trust dengan mahasiswa. Komunikasi pembimbing dengan pasien, keluarga juga terjalin baik.

Sikap dan perilaku dari pembimbing klinik dapat menjadi energi positif bagi mahasiswa untuk semakin semangat dan ingin mengetahui banyak hal-hal tentang nilai-nilai keperawatan. Hal ini merupakan merupakan pengalaman berharga bagi mahasiswa untuk 
menjalani perannya kedepan setelah menyelesaikan studinya menjadi perawat yang berkompeten dibidangnya sesuai hak dan kewewenangannya (Tursina, Safaria, \& Mujidin, 2016)

\section{KESIMPULAN}

Ada pengaruh antara pelatihan preceptorship terhadap pengetahuan dan sikap pembimbing klinik, yang berdampak pada respon kepuasan mahasiswa saat dilakukan bimbingan di klinik oleh para pembimbing klinik yang telah mengikuti pelatihan preceptorship dengan respon sangat baik. Mengingat pentingnya pelatihan preceptorship tersebut maka diharapkan semua pembimbing klinik tempat lahan praktik mahasiswa perlu mendapatkan pelatihan perceptorship.

\section{DAFTAR PUSTAKA}

Akram, A. S., \& Mohamad, A. (2018). The Role of Clinical Instructor in Bridging the Gap between Theory and Practice in Nursing Education. International Journal of Caring Sciences, Volume 11(Issue 2), Page 876.

Bura Mare, A. C., \& Meidiana Dwidiyanti. (2018). Literature Review: Menjadi Preceptor yang Baik pada Program Preceptorship Perawat Baru. Jurnal Ners LENTERA, Vol. 6, No. 1. Retrieved from Email: agustinachriswinda@yahoo.com
Cederbaum, J., \& Klusaritz, H. A. (2009). Clinical Instruction: Using the Strengths-Based Approach with Nursing Students. Journal of Nursing Education, Vol. 48, No. 8 4, 48(8):423-424. https://doi.org/10.3928/0148483 4-20090518-01

Dadgaran, I., Parvizy, S., \& Peyrovi, H. (2012). A global issue in nursing students"clinical learning: Theory-practice gap. Elsevier, Procedia-Social and Behavioral Sciences 47, 1713 1718. https://doi.org/doi: 10.1016/j.sbspro.2012.06.888

Niederriter, J. (2017). Nursing Students' Perceptions on Characteristics of an Effective Clinical Instructor. SAGE Open Nursing, $3 \quad$ : $1-8$. https://doi.org/DOI:

$10.1177 / 2377960816685571$ journals.sagepub.com/home/son

O'Connor, A. B. (2015). Clinical Intruction and Evaluation (Third Edition). Retrieved from www.jblearning.com.

The Preceptor Role in Health Systems Management. (2019). Retrieved from E-mail: mhade@luc.edu

Tursina, A., Safaria, T., \& Mujidin. (2016). Pengaruh Bimbingan Preceptorship Model Kognitif Sosial Terhadap Peningkatan Kompetensi Klinik pada Mahasiswa. PSIKOPEDAGOGIA, Vol. 5, No. 1, 79-87. 